\title{
A Phase I Trial of Temsirolimus and Pemetrexed in Patients with Advanced Non-Small Cell Lung Cancer
}

\author{
Saiama N. Waqar Maria Q. Baggstrom Daniel Morgensztern Kristina Williams
}

\section{Caron Rigden Ramaswamy Govindan}

Division of Medical Oncology, Department of Internal Medicine, Washington University School of Medicine, St. Louis, Mo., USA

\section{Key Words}

Temsirolimus · Pemetrexed · Non-small cell lung cancer · Phase I trial

\section{Abstract}

Background: Pemetrexed is an antifolate chemotherapeutic agent approved for use in non-small cell lung cancer (NSCLC). The mammalian target of rapamycin (mTOR) pathway is implicated in lung cancer development and inhibited by temsirolimus. Methods: We performed a phase I study evaluating the combination of pemetrexed and temsirolimus in advanced non-squamous NSCLC. Results: Eight patients were enrolled in this study. The dose-limiting toxicities included grade 4 thrombocytopenia, grade 3 leukopenia and grade 3 neutropenia. The maximum tolerated dose was determined to be pemetrexed $375 \mathrm{mg} / \mathrm{m}^{2}$ intravenously on day 1 and temsirolimus $25 \mathrm{mg}$ intravenously on days 1,8 and 15. No objective responses were noted and 3 patients had stable disease as the best response. Conclusion: The combination of pemetrexed and temsirolimus is feasible and well tolerated. This combination may be further evaluated in patients with mTOR pathway activation, particularly in those with TSC1 or STK11 mutations.

(c) 2016 S. Karger AG, Basel

\section{Introduction}

Lung cancer remains the leading cause of cancer-related death in the USA, accounting for more deaths than cancer of the breast, colon and pancreas combined [1]. Non-small cell lung cancer (NSCLC) accounts for $87 \%$ of lung cancers, and approximately $40 \%$ of patients present with metastatic disease treated with palliative systemic therapy $[2,3]$. Platinum-containing chemotherapy regimens have been shown to improve survival and quality of life in patients with good performance status (PS) [4]. Small molecule inhibitors of the epidermal growth factor receptor (EGFR) gene and anaplastic lymphoma kinase $(A L K)$ gene are used in patients with activating EGFR mutations and ALK gene rearrangements, respectively [5-7]. For patients with a poor PS, no targetable molecular alterations or tumor progression after front-line platinum-doublet therapy, the treatment options are limited. Single-agent chemotherapy is recommended for eligible patients with a good PS [8].

Pemetrexed is a folate antagonist approved for the treatment of patients with metastatic non-squamous lung cancer. The activity of pemetrexed is comparable to ap-

\section{KARGER}

E-Mail karger@karger.com

www.karger.com/che
(C) 2016 S. Karger AG, Basel

0009-3157/16/0613-0144\$39.50/0
Ramaswamy Govindan, MD, Professor of Medicine

Division of Medical Oncology, Department of Internal Medicine Washington University School of Medicine 660 S. Euclid, Box 8056, St Louis, MO 63110 (USA)

E-Mail rgovinda@dom.wustl.edu 
proved second-line agents. In a randomized trial comparing pemetrexed to docetaxel, although there were no significant differences in median overall survival, the toxicity profile favored pemetrexed with less grade 3 or 4 toxicities including neutropenia (5.3 vs. $40.2 \%$ ), febrile neutropenia (1.9 vs. $12.7 \%$ ), neutropenia with infections (3.3 vs. $0 \%$ ), hospitalizations with neutropenic fever (13.4 vs. $6.4 \%$ ), the use of granulocyte colony-stimulating factor support (2.6 vs. $19.2 \%$ ) and all-grade alopecia (6.4 vs. $37.7 \%)[9,10]$.

Activation of the mammalian target of rapamycin (mTOR) pathway has been implicated in the development of several malignancies, including lung cancer [11, 12]. Temsirolimus is an inhibitor of mTOR kinase and has demonstrated antiproliferative and antiangiogenic activity in multiple tumor types. Temsirolimus is generally well tolerated, with grade 3 or 4 toxicities being observed including hyperglycemia (17\%), hypophosphatemia (13\%), anemia (9\%) and hypertriglyceridemia (6\%) $[13,14]$. In a phase II study of multiple dose levels of temsirolimus, the $25 \mathrm{mg}$ dose was found to be equally efficacious in higher doses, and was therefore chosen as the optimal dose for monotherapy [15]. In the phase II study reported by Reungwetwattana et al. [16], 55 patients with untreated NSCLC received $25 \mathrm{mg}$ temsirolimus intravenously (i.v.) on a weekly basis. The clinical benefit rate was $35 \%$, with a partial response in 4 patients and stable disease for $\geq 8$ weeks in 14 patients.

Pemetrexed and temsirolimus target different cellular pathways and may have synergistic activity when given in combination $[17,18]$. In a preclinical study, rapamycin and pemetrexed had synergistic effects in inhibiting the proliferation of NSCLC cells through downregulation of thymidylate synthase by rapamycin increasing the activity of pemetrexed [17]. Pemetrexed has also been shown to inhibit mTOR through the accumulation of ZMP, a substrate of the secondary target aminoimidazoecarboxamide ribonucleotide formyltransferase (AICART) [18]. Furthermore, temsirolimus is well tolerated and has nonoverlapping toxicities with pemetrexed. In a phase I study including 24 patients treated with pemetrexed and everolimus administered either daily or weekly, there were 3 partial responses [19]. The combination was considered safe although the frequency and severity of adverse events was higher than expected for each drug alone. The most common grade 3 and 4 toxicities were neutropenia, thrombocytopenia and dyspnea. We therefore conducted a phase I study on temsirolimus in combination with pemetrexed in order to establish a safety profile.

Temsirolimus and Pemetrexed in Patients with Advanced NSCLC
Table 1. Dose escalation scheme

\begin{tabular}{rll}
\hline Cohort & $\begin{array}{l}\text { Pemetrexed on day } 1 \\
\text { every } 3 \text { weeks }\end{array}$ & $\begin{array}{l}\text { Temsirolimus weekly } \\
\text { on days } 1,8 \text { and } 15\end{array}$ \\
\hline-1 & $375 \mathrm{mg} / \mathrm{m}^{2}$ & $15 \mathrm{mg}$ \\
1 & $500 \mathrm{mg} / \mathrm{m}^{2}$ & $15 \mathrm{mg}$ \\
2 & $500 \mathrm{mg} / \mathrm{m}^{2}$ & $20 \mathrm{mg}$ \\
3 & $500 \mathrm{mg} / \mathrm{m}^{2}$ & $25 \mathrm{mg}$ \\
\hline
\end{tabular}

\section{Methods}

Patients with histologically or cytologically confirmed advanced non-squamous NSCLC were enrolled in this study. Eligibility criteria allowed prior therapies, as long as treatment was completed at least 4 weeks prior to study entry. Patients who had not received prior therapy were eligible if they were not candidates for platinum-based chemotherapy. Other eligibility criteria included an Eastern Cooperative Oncology Group PS of 0-2, an age of $\geq 18$ years and adequate marrow function (ANC $\geq 1,500$ cells/ $\mathrm{mm}^{3} ; \mathrm{Hb} \geq 9 \mathrm{~g} / \mathrm{dl}$; platelets $\geq 100,000 / \mathrm{mm}^{3}$ ), hepatic function (total bilirubin $\leq 1.5 \mathrm{mg} / \mathrm{dl}$; AST/ALT $\leq 2.5$ times the upper limit of normal or $\leq 5$ times the upper limit of normal for patients with liver metastasis) and renal function (creatinine $<2.0 \mathrm{mg} / \mathrm{dl}$ and/or creatinine clearance $\geq 60 \mathrm{ml} / \mathrm{min}$ ). Patients were required to have serum cholesterol $<350 \mathrm{mg} / \mathrm{dl}$ and serum triglycerides $<300 \mathrm{mg} / \mathrm{dl}$. The washout period for prior chemotherapy or surgery was 4 weeks and 2 weeks for radiation therapy. Key exclusion criteria included prior treatment with pemetrexed, severe acute or chronic medical conditions and symptomatic brain metastasis. Written informed consent was obtained from all patients, and the trial was approved by the Washington University Human Research Protection Office.

The starting dose (dose level 1) of pemetrexed was $500 \mathrm{mg} / \mathrm{m}^{2}$ administered i.v. on day 1 of each 21 -day cycle over $10 \mathrm{~min}$, and $15 \mathrm{mg}$ temsirolimus i.v. over $30 \mathrm{~min}$ on days 1,8 and 15 of each cycle (table 1). Patients were premedicated with steroids (dexamethasone $10 \mathrm{mg}$ or equivalent) i.v., $5-\mathrm{HT}_{3}$ receptor antagonists (palonosetron $0.25 \mathrm{mg}$ or equivalent) and antihistamines (diphenhydramine $50 \mathrm{mg}$ or equivalent) prior to treatment on the days that included both pemetrexed and temsirolimus. Patients were premedicated with $50 \mathrm{mg}$ diphenhydramine i.v. on the days that only temsirolimus was administered. Routine supportive care was permitted. However, patients were recommended to avoid potent CYP3A4 inhibitors and inducers.

A modified Fibonacci dose escalation scheme with a minimum of 3 patients per cohort was used [20]. Dosing began at dose level 1 and was escalated or de-escalated as appropriate. If a dose-limiting toxicity (DLT) occurred in 1 out of the first 3 patients, an additional 3 patients were accrued at the same dose level. If $>2$ patients in a given cohort experienced a DLT, the cohort would have exceeded the maximum tolerated dose (MTD) and a minimum of 6 patients were accrued at the next lower dose level.

All toxicities were graded according to the National Cancer Institute's Common Terminology Criteria for Adverse Events v3.0. The MTD was defined as the dose level immediately below the dose at which 2 patients of a cohort experienced a DLT. DLT was de-

Chemotherapy 2015-16;61:144-147 145 
fined as any of the following during the first cycle of treatment: grade 4 neutropenia for $>7$ days, neutropenic fever, grade 4 anemia, grade 3 or higher thrombocytopenia and grade 3 or higher toxicity determined to be reasonably related to protocol therapy or any toxicity requiring a delay of protocol therapy of $>14$ days during the first cycle of therapy (6 weeks). Patients had weekly complete blood counts and toxicity assessments performed during the first cycle of therapy to evaluate for DLTs. Physical exams were performed every 3 weeks during the first cycle of therapy.

Patients were evaluated for response radiographically every 2 cycles. Treatment continued until progression of disease, DLT or if the patient chose to withdraw from study therapy. Patients who experienced DLTs were removed from the study and were not evaluated for response but were evaluable for toxicity. Response was defined by Response Evaluation Criteria in Solid Tumors (RECIST) version 1.0.

\section{Results}

Between December 2009 and February 2011, 8 patients were enrolled in this study, i.e. 6 men and 2 women. The median age of the patients was 58.5 years (49-76 years). One patient had a PS of 0,6 patients had a PS of 1 and 1 patient had a PS of 2 . Five patients had received 1 prior line of systemic platinum-doublet therapy and 3 were treatment naïve. Five patients had received prior radiation therapy, i.e. whole-brain radiation in 2 and thoracic radiation in 3 . Patients were treated at 2 dose levels: 2 received dose level 1 and 6 received dose level -1 . They received a mean of 2 cycles ( 6 weeks) of therapy.

At the first dose level, 1 patient completed 1.5 cycles and experienced DLTs, i.e. grade 4 thrombocytopenia, grade 3 leukopenia and grade 3 neutropenia (table 2). A second patient treated at this dose level also developed grade 3 leukopenia and so the decision was made to decrease to dose level -1 , comprising pemetrexed $375 \mathrm{mg} /$ $\mathrm{m}^{2}$ on day 1 and temsirolimus $15 \mathrm{mg}$ i.v. weekly on days 1,8 and 15 . At dose level -1 , no DLTs were observed and so this was declared the MTD.

Four patients were not evaluable for response. One patient in cohort 1 , who experienced the DLTs grade 4 thrombocytopenia, grade 3 leukopenia and grade 3 neutropenia, was removed from the study at the discretion of the investigators. An additional patient was removed from the trial by the treating physician, and 2 with a poor PS expired prior to the 6-week scan, even though no DLTs had been observed. Four patients were evaluable for antitumor activity. Two of these had stable disease of 12 weeks' duration, 1 had stable disease of 4 weeks' duration and 1 experienced disease progression. There were no responses observed.
Table 2. Toxicity profile

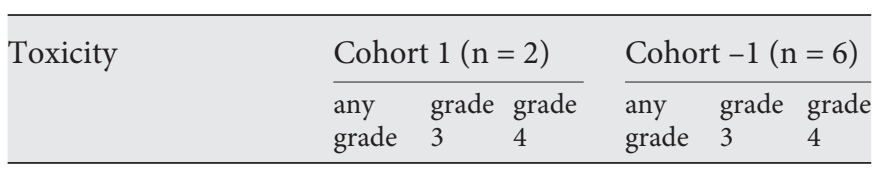

Hematologic

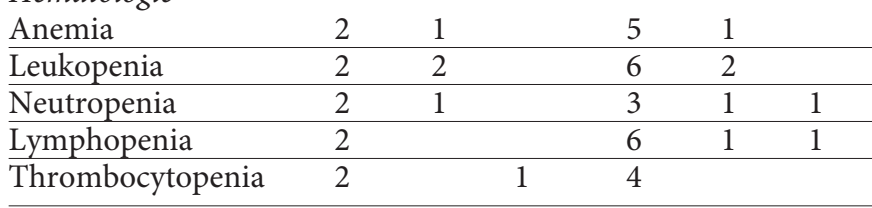

Nonhematologic

\begin{tabular}{llll} 
Fatigue & 1 & 2 & 1 \\
\hline Anorexia & 3 & & \\
\hline
\end{tabular}

\begin{tabular}{llll}
\hline Anorexia & 3 & & \\
\hline Nausea & 1 & 3 & \\
\hline Vomiting & & 1 & \\
\hline Diarrhea & 1 & 1 & \\
\hline Constipation & 1 & 3 & \\
\hline Pain & & 2 & \\
\hline Skin rash & 1 & 2 & 2 \\
\hline Dyspnea & & 1 & 1 \\
\hline Hypoxia & 1 & 1 & \\
\hline Headache & 2 & \\
\hline Insomnia & 1 & 1 & \\
\hline Depression & & & \\
\hline Confusion & & 2 & \\
\hline Creatinine elevation & & 4 & 3 \\
\hline Hyperglycemia & & 2 & \\
\hline Hyponatremia & & 2 & \\
\hline Hypocalcemia & 2 & 1 & \\
\hline Hypomagnesemia & & 1 & \\
\hline Hypertriglyceridemia & & 4 & \\
\hline Hypoalbuminemia & 2 & & \\
\hline Hyperbilirubinemia & 1 & 5 & 1 \\
\hline Elevated AST & & 3 & 1 \\
\hline Elevated ALT & & & \\
\hline Proteinuria & 1 & & \\
\hline Watering eyes & & & \\
\hline
\end{tabular}

\section{Discussion}

The combination of pemetrexed and temsirolimus was administered to patients with metastatic NSCLC. The MTD of pemetrexed was $375 \mathrm{mg} / \mathrm{m}^{2}$ on day 1 and the MTD of temsirolimus was $15 \mathrm{mg}$ i.v. weekly. The lack of response is not surprising in this small cohort, comprising mostly patients who had failed prior platinum-doublet therapy and including a patient with a PS of 2 . Patients with a poor PS remain a challenging group to treat, and more clinical trials are needed for this population in order to meet this need. Future trials should examine the activity of this combination in patients with mTOR pathway activa- 
tion in NSCLC, particularly those with TSC1 or STK11 mutations, as these genomic alterations have been associated with a response to mTOR inhibitor therapy [21, 22].

\section{Disclosure Statement}

The content of this article is the sole responsibility of the authors and does not necessarily represent the official views of the NIH.

\section{Acknowledgements}

This publication was supported by the National Cancer Institute of the National Institutes of Health (NIH), grant No. 1K12CA167540 and the Clinical Translational Science Award (CTSA) program of the National Center for Advancing Translational Sciences at the NIH, grant No. UL1RR024992.

\section{References}

1 Siegel RL, Miller KD, Jemal A: Cancer statistics, 2015. CA Cancer J Clin 2015;65:5-29.

2 Govindan R, Page N, Morgensztern D, et al: Changing epidemiology of small-cell lung cancer in the United States over the last 30 years: analysis of the surveillance, epidemiologic, and end results database. J Clin Oncol 2006;24:4539-4544.

3 Morgensztern D, Ng SH, Gao F, Govindan R: Trends in stage distribution for patients with non-small cell lung cancer: a National Cancer Database survey. J Thorac Oncol 2010;5:2933.

4 Schiller $\mathrm{JH}$, Harrington D, Belani $\mathrm{CP}$, et al: Comparison of four chemotherapy regimens for advanced non-small-cell lung cancer. $\mathrm{N}$ Engl J Med 2002;346:92-98.

5 Rosell R, Carcereny E, Gervais R, et al: Erlotinib versus standard chemotherapy as firstline treatment for European patients with advanced EGFR mutation-positive non-smallcell lung cancer (EURTAC): a multicentre, open-label, randomised phase 3 trial. Lancet Oncol 2012;13:239-246.

6 Shaw AT, Kim DW, Nakagawa K, et al: Crizotinib versus chemotherapy in advanced ALKpositive lung cancer. N Engl J Med 2013;368: 2385-2394.

7 Kuo SC, Hsu PC, Chen CH, et al: Overall response to first-line tyrosine kinase inhibitor and second-line chemotherapy is predictive of survival outcome in epidermal growth factor receptor-mutated adenocarcinoma. Chemotherapy 2014;60:201-210.

8 Ettinger DS, Akerley W, Bepler G, et al: Nonsmall cell lung cancer. J Natl Compr Canc Netw 2010;8:740-801.
9 Hanna N, Shepherd FA, Fossella FV, et al: Randomized phase III trial of pemetrexed versus docetaxel in patients with non-smallcell lung cancer previously treated with chemotherapy. J Clin Oncol 2004;22:1589-1597.

10 Igawa $S$, Ryuge $S$, Wada $M$, et al: Pemetrexed for previously treated patients with non-small cell lung cancer and differences in efficacy according to thymidylate synthase expression. Chemotherapy 2012;58:313-320.

11 Schmelzle T, Hall MN: TOR, a central controller of cell growth. Cell 2000;103:253-262.

12 Wislez M, Spencer ML, Izzo JG, et al: Inhibition of mammalian target of rapamycin reverses alveolar epithelial neoplasia induced by oncogenic K-ras. Cancer Res 2005;65:32263235.

13 Hudes G, Carducci M, Tomczak P, et al: Temsirolimus, interferon alfa, or both for advanced renal-cell carcinoma. N Engl J Med 2007;356:2271-2281.

14 Atkins MB, Hidalgo M, Stadler WM, et al: Randomized phase II study of multiple dose levels of CCI-779, a novel mammalian target of rapamycin kinase inhibitor, in patients with advanced refractory renal cell carcinoma. J Clin Oncol 2004;22:909-918.

15 Atkins MB, Hidalgo M, Stadler WM, et al: Randomized phase II study of multiple dose levels of CCI-779, a novel mammalian target of rapamycin kinase inhibitor, in patients with advanced refractory renal cell carcinoma. J Clin Oncol 2004;22:909-918.
16 Reungwetwattana T, Molina JR, Mandrekar SJ, et al: Brief report: a phase II 'window-ofopportunity' frontline study of the MTOR inhibitor, temsirolimus, given as a single agent in patients with advanced NSCLC, an NCCTG study. J Thorac Oncol 2012;7:919-922.

17 Kawabata S, Chiang CT, Tsurutani J, et al: Rapamycin downregulates thymidylate synthase and potentiates the activity of pemetrexed in non-small cell lung cancer. Oncotarget 2014; 5:1062-1070

18 Racanelli AC, Rothbart SB, Heyer CL, Moran RG: Therapeutics by cytotoxic metabolite accumulation: pemetrexed causes ZMP accumulation, AMPK activation, and mammalian target of rapamycin inhibition. Cancer Res 2009;69:5467-5474.

19 Vansteenkiste J, Solomon B, Boyer M, et al Everolimus in combination with pemetrexed in patients with advanced non-small cell lung cancer previously treated with chemotherapy: a phase I study using a novel, adaptive Bayesian dose-escalation model. J Thorac Oncol 2011;6:2120-2129.

20 Eisenhauer EA, O'Dwyer PJ, Christian M, Humphrey JS: Phase I clinical trial design in cancer drug development. J Clin Oncol 2000; 18:684-692.

21 Iyer G, Hanrahan AJ, Milowsky MI, et al: Genome sequencing identifies a basis for everolimus sensitivity. Science 2012;338:221.

22 Gill RK, Yang SH, Meerzaman D, et al: Frequent homozygous deletion of the LKB1/ STK11 gene in non-small cell lung cancer. Oncogene 2011;30:3784-3791. 